\title{
Revealing an Endemic Herbivore-Palm Interaction in Remote Desert Oases of Baja California
}

\author{
Elisabet V. Wehncke ${ }^{1,2}$, Xavier López-Medellín ${ }^{1,2}$, Michael Wall ${ }^{2}$, Exequiel Ezcurra ${ }^{3}$ \\ ${ }^{1}$ Centro de Investigación en Biodiversidad y Conservación, Dept. Manejo de Recursos Naturales y Educación Ambiental, Universidad \\ Autónoma del Estado de Morelos, Cuernavaca, Mexico; ${ }^{2}$ Biodiversity Research Center of the Californias, San Diego Natural History \\ Museum, San Diego, USA; ${ }^{3}$ UC Institute for Mexico and the United States, University of California, Riverside, USA. \\ Email: lizwehncke@gmail.com
}

Received December 22 ${ }^{\text {nd }}, 2012$; revised January $25^{\text {th }}, 2013$; accepted February $2^{\text {nd }}, 2013$

\begin{abstract}
In the Central Desert of northern Baja California, blue fan palm populations (Brahea armata) are found as isolated oases on mountaintops and along canyons with ephemeral flow conditions. Here, the effect of the interaction between the larva of an endemic moth, Litoprosopus bajaensis, and this endemic blue fan palm was documented for the first time. We registered the phenology of palms by counting the number of shoots with flowers or fruits, assessing their damage and calculating the reproductive success per individual palm within three populations: San Pedro Martir, Cataviña, and La Libertad. Palm populations were severely impacted by this larva, causing high damage to the inflorescences. No differences were found in the number of inflorescence stems produced and damaged among study sites; but the reproductive success of palms was significantly higher in Cataviña than in the other sites during the entire sampling period, and consequently an important proportion of stems escaped from the herbivore predation. We suggest that differences among sites may be explained by the fact that Cataviña is the only alluvial canyon and can be considered an area of high nutrient uptake, resource availability, and rooting depths. In contrast the other two are bedrock canyons, where water runs intensely, sweeping away great portions of the nearby vegetation. Cataviña received the highest precipitation during the winter season of 2010 allowing a continuous production of inflorescence stems and fruits. This preliminary study reveals a new endemic interaction, it occurrence at population and regional levels, and highlights the role of desert oases as resource patches and connectivity pathways for mobile insects. Finally, it also highlights the effects of different water flow dynamics and water pulses in providing an opportunity window of escape from predation for host plant species living in desert environments.
\end{abstract}

Keywords: Baja California; Blue Fan Palm; Insect Herbivory; Lepidoptera; Water Pulses

\section{Introduction}

A fundamental goal in the study of herbivore-plant interactions is to understand how and under what circumstances insect herbivory affects the fitness and dynamics of plant populations. Insect herbivores can strongly influence phenology, physiology and morphology of individual host plants and reduce growth, flower and seed production sometimes having large-scale effects on natural plant communities [1-5]. On the other hand, the distributions of insect species can be influenced by individual traits such as dispersal ability, sexual attraction, or aggregation [6,7], by habitat factors such as resource density and heterogeneity [8], and by temporal climatic variations [9], such as peaks or pulses of water. Thus, habitat fragmentation or how resources are distributed in space and time has important effects on insect population dynamics [10]. When habitat is fragmented the dispersal behavior of insects explains much of the variation of population densities throughout the resource patches [11]. Thus, the link between ecological processes and spatial patterns is of the outmost importance in the conservation of endangered species as well as in pests and invasions control by relating the spatial distribution of both, insect populations and resources to damage [12-14].

Since the influences of top-down (predation, including herbivory) and bottom-up (resource availability) forces may change systematically along environmental gradients of productivity [15-20], comparisons among different populations and areas may help to explore connections between herbivory and environmental conditions as well as to help to detect variations related to environmental change. In ecosystems such as deserts, vertebrate herbivores apparently influence the growth rates [21], morphology [22], recruitment [23], and community dynamics $[24,25]$ of plants. Although a wide range of spa- 
tial patterns and life-history traits are described in insect populations [26] and occasional large effects of insect herbivores particularly on palms are documented, evidence of the direct effects of invertebrate herbivory on desert or semi-arid plants is limited, particularly the longlived dominant species [14,27-29].

In the northern desert of the Baja California peninsula, remnant vegetation patches from an ancient paratropical forest have remained as isolated oases on mountaintops and along canyons where wetter conditions are preserved [30-32]. Dominated by the endemic blue fan palm ( $\mathrm{Bra}-$ hea armata, Arecaceae), these oases seem to keep a certain degree of connectedness, although their effectiveness as corridors for the fauna and flora remains unknown. Surrounded by a desert matrix and withstanding extreme climatic conditions and erratic water availability, blue fan palm populations are located at the northwestern boundaries of the distribution of the palm family in America $[31,33]$. Species living at the boundaries of their distributions have recently raised special attention for the preservation of biodiversity, since they provide an opportunity for studying limits to plant and/or animal survival and therefore should be considered particularly relevant in the study of species responses to fluctuating environments.

Here, we report preliminary information on a new endemic invertebrate herbivore-palm interaction occurring in oases of the Central Desert Region of Baja California, Mexico. The larva of a moth species that coincides with an endemic Lepidoptera discovered by Brown and Faulkner in 1997 impacted the inflorescences of the endemic blue fan palm populations. This moth species was known only from the northern portion of the Vizcaino Desert in Baja California, Mexico. Brown and Faulkner described six adults of Litoprosopus bajaensis (Noctuidae), which is geographically isolated and morphologically distinct from its congeners. Nothing is known about its natural history; however, based on the life history information of L. coachella Hill, the closest species geographically (restricted to southern California), it has been suggested that the larva of this moth feeds on the flowers, buds, and possibly fruits of fan palms in the genus Washingtonia (Arecaceae), $W$. filifera (Linden) Wendl. and $W$. robusta Wendl. [34,35].

\section{Methodology}

\subsection{Study Site}

The blue fan palm, the dominant tree species in the three study sites is endemic to the northern part of the Baja California peninsula and the neighboring Angel de La Guarda Island [36]. Blue fan palm populations range from the Sierra Juarez (30 km south of the US-Mexico border) to the Sierra La Libertad (above $28^{\circ} \mathrm{N}$ ). According to Shreve (1951) [37], blue fan palms are phytogeographically found in two different subdivisions of the Sonoran Desert: the Lower Colorado Valley, and the Vizcaíno region also known as the Central Desert of Baja California [33]. We selected three blue fan palm populations along their distribution (San Pedro Martir, 30 $32.3^{\prime} \mathrm{N}$, $115^{\circ} 08.5^{\prime} \mathrm{W}$, elevations: 689 - $769 \mathrm{~m}$; Cataviña, $29^{\circ} 450^{\prime} \mathrm{N}$, 114 $400^{\prime} \mathrm{W}$, elevations: 609 - $617 \mathrm{~m}$; and La Libertad, $28^{\circ} 200^{\prime} \mathrm{N}, 113^{\circ} 410^{\prime} \mathrm{W}$; elevations: $\left.402-428 \mathrm{~m}\right)$. The last two represent main basins located within the Natural Protected Area Valle de los Cirios and are located on the Pacific slope of the Baja California ranges. Sites are separated approximately $200 \mathrm{~km}$ from each other in a straight line Figure 1. San Pedro Martir is composed of
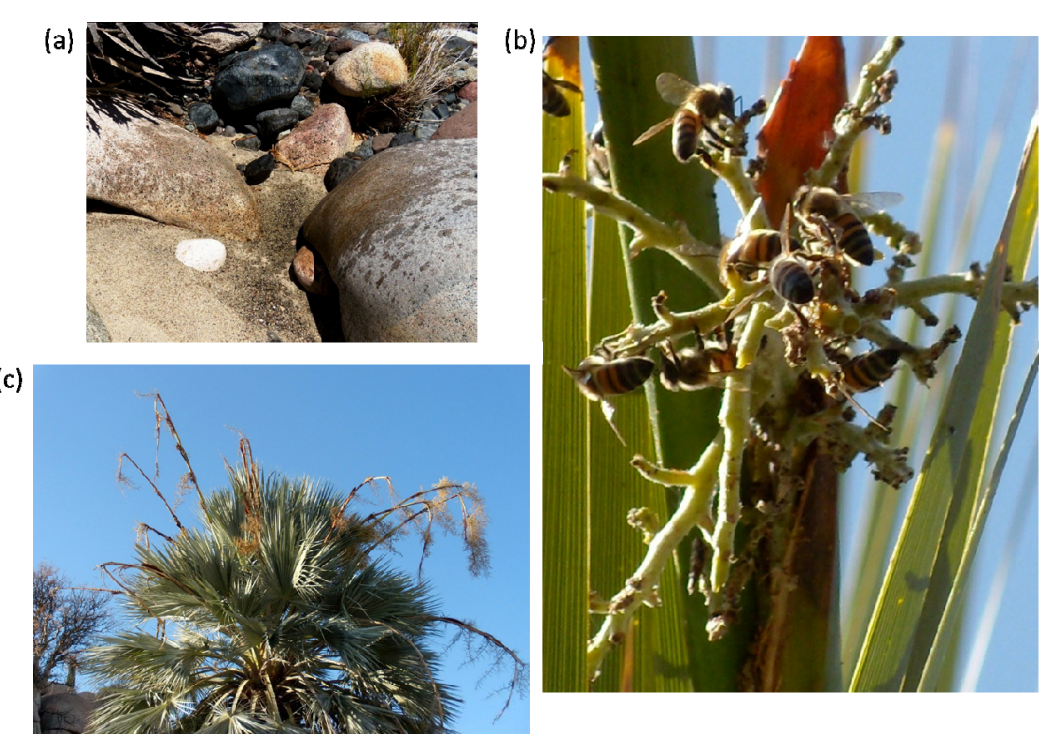

Figure 1. Location of study sites (San Pedro Martir, Cataviña, and La Libertad), and pictures of study plots established within sites, in northern Baja California, Mexico. 
large granite blocks that drop off sharply towards the eastern desert floor, with streams that are fed by water collected in the higher elevations during the winter months. We established four plots of approximately 1 ha $(200 \times 50 \mathrm{~m})$ in all sites. On each site, plots were located $>30 \mathrm{~m}$ and $<3 \mathrm{~km}$ apart.

The southern part of La Libertad has more tropical influence from summer rains, Cataviña is an intermediate point, and San Pedro Martir is influenced by winter rains. Two periods of rain normally occur in Cataviña, one in winter (November-April) and the other in late summer (August-October). Usually the driest period is from late spring through summer (May-September). Cataviña normally receives around $110-150 \mathrm{~mm}$ of annual rainfall [38], while in La Libertad, winter precipitation is less abundant and summer tropical storms can bring considerable precipitation to the mountains.

Although palm data analyzed in this study correspond to the fall and winter seasons of 2009 and 2010, we experienced the influence of several water pulses of diverse intensities since June 2006. Data on precipitation were obtained from the National Water Commission of Mexico, from the closest meteorological stations to our study plots. We used data of the meteorological stations at San Felipe (Station 2148: 31 $1^{\circ} 139 " \mathrm{~N}, 114^{\circ} 50^{\prime} 7 " \mathrm{~W}$; elevation $10 \mathrm{~m}$ ); Cataviña (Station 2051, San Luis: $29^{\circ} 43^{\prime} 38^{\prime \prime N}$, $114^{\circ} 42^{\prime 3} 39^{\prime \prime W}$; elevation $480 \mathrm{~m}$ ); and Villa Jesús María (Station 2012 Ejido Jesús María Morelos: 28¹8'0"N, $114^{\circ} 1 ' 33 " \mathrm{~W}$; elevation $20 \mathrm{~m}$ ). The station of San Felipe is on the sea of Cortés and about $65 \mathrm{~km}$ in a straight line from our study sites in arroyo El Berrendo, Sierra de San Pedro Mártir; the station of San Agustin is about $35.5 \mathrm{~km}$ and the one of San Luis at $3.5 \mathrm{~km}$ from our study site at arroyo Santa Inez, Cataviña; and the station of Villa Jesús María is $33.5 \mathrm{~km}$ from our study sites in arroyo El Toro, Sierra de La Libertad. These stations were selected because they represent the most reliable and continuous database that exist for the period needed in this study. However, they might be underestimating the real precipitation values inside the canyons. Weather forecasting in Baja California has been hindered by a lack of reliable records; therefore, accurate rainfall statistics for multiyear periods are sometimes not possible, such as the case of the San Felipe station.

\subsection{Study Species}

Knowledge of Noctuidae moths (Insecta: Lepidoptera) [39], and particularly the lepidopterous fauna of the peninsula of Baja California has increased over the last years [40]. However, numerous endemic taxa and their natural histories and interactions with the regional flora have not been described. Thorough taxonomic treatments and/or inventories have been compiled by Brown (2004) [40] for 11 families of Lepidoptera from Baja California which represent $10 \%$ of the Lepidoptera fauna. According to this author, some patterns have been identified: 1 ) endemism seems to range from moderate to low and it is expressed solely at lower taxonomic levels; and 2) species richness in most groups is highest at the northernmost and southernmost extremes of the peninsula and lowest in the middle. Eight species are included in the genus Litoprosopus [34,41]: L. bahamensis, L. bajaensis, L. coachella, L. confligens, L. futilis, L. haitiensis, L. hatuey (Poey), and L. punticosta. These species are distributed from southern United States through Central America with few records from northern South America [34]. These authors mention that L. bajaensis can be superficially distinguished from all other species of Litoprosopus by its nearly uniform pale fawn-gray forewing color, while most species in the same genus have varying shades of brown on the forewing. Geographically close, $L$. coachella is restricted to southern California, while $L$. bajaensis is distributed south to the El Vizcaíno Desert of Baja California, Mexico [34].

Palms inhabit the lower parts of canyons which conserve subsurface flow and up on mesas; they are also associated to granite rock substrate of the northern mountain ranges of the peninsula [31-33], and they seem to be tolerant to moderately salty soils (Wehncke, pers. obs.). They belong to the Corypheae, one of the less specialized tribes within the subfamily Coryphoideae, with more primitive leaf forms, flowers, and pollen [42,43]. Maximum height for $B$. armata was measured up to $23 \mathrm{~m}$, in La Libertad (Wehncke, pers. obs.). This slow-growing palm species can be reproductive when reaching ca. 2-m height. Flowers are arranged in clusters of many small whitish bisexual blossoms that appear in multiple branching inflorescences up to 5 -m length $[43,44]$. The oneseeded rounded fruits are of medium size $(2.0-2.5 \mathrm{~cm})$, with relatively little mesocarp and are brownish black when mature [44,45].

\subsection{Natural History Observations and Data Collection}

We collected phenological data during four sampling visits (in July and November, 2009 and in May and September, 2010) in Cataviña and La Libertad. Data from San Pedro Martir was collected during three sampling visits: July, 2009 and June and November, 2010. Time of visits was programmed to coincide with the flowering period of the blue fan palms. First, we registered the number of adult palms with signs of damage. Then, in order to have more precise quantitative measurements of the impact of the larva to the palm populations and to determine how it affects their reproductive effort, we counted the number of inflorescence stems with flowers 
and fruits that were damaged, per individual palm. We then estimated the reproductive effort of each palm for all populations as the total number of stems with fruits observed out of the total number of stems produced by each individual palm. The relative number of stems produced and damaged were recorded in different categories and compared among sites, as well as the relative frequencies of the reproductive success.

\section{Results}

In June 2006, we observed for the first time blue fan palms producing high quantities of a sugary fluid from the inflorescence stems of the San Pedro Martir populations that dropped down to the ground. In April 2008 we evidenced the same process in La Libertad, the southern distribution range of blue fan palm populations Figure 2(a). We observed that these fluids attracted a significant number of insects (bees, wasps, beetles, flies) around the

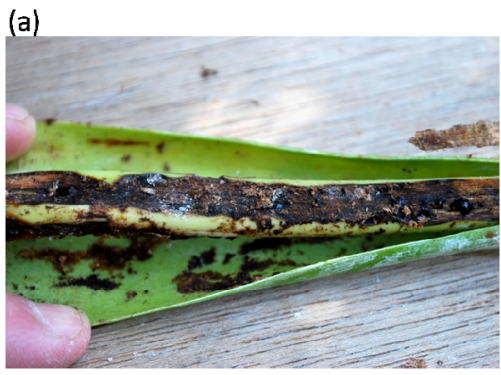

buds and inflorescences, which sucked this sugary substance Figure 2(b). Not only insects, but also cattle took advantage of this sugary fluid from the lowest stems. After two months after bud emergence, the scenario was of severe damage to the inflorescence stems of most individual palms in these populations Figure 2(c), which worsened after the heavy rains of El Niño event in July 2007.

We collected inflorescence stems in order to find the source of the damage, and observed that a small larva of a moth was living inside the stems, preventing any possibility of flower development Figure 3(a). Although Brown and Faulkner described in 1997 six adults of Lepidoptera collected in the Cataviña area, and named it Litoprosopus bajaensis an endemic species of the Central Desert Region, no information existed about the natural history of this species. Researchers at the San Diego Natural History Museum confirmed that the larva corresponds to the larvae of L. bajaensis Figure 3(b). (b)

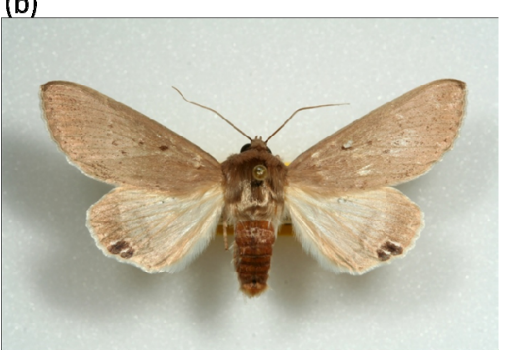

Figure 2. Fluids on underlying rocks produced by blue fan palm as a response to damage by L. bajaensis (a); Apis mellifera feeding on fluids induced by damage to B. armata inflorescence (b); broken and damaged inflorescences of $B$. armata (c).

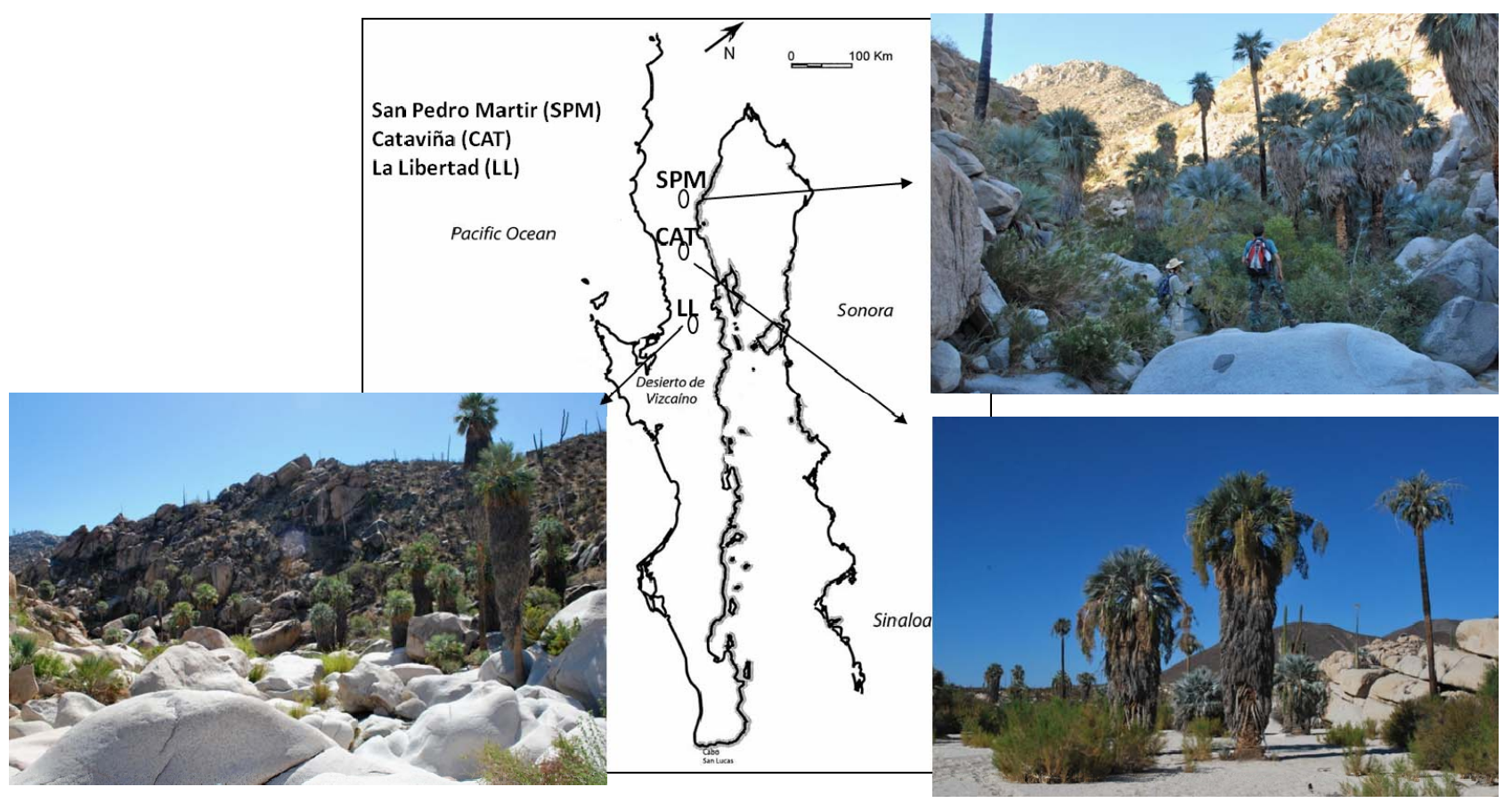

Figure 3. Damage produced by L. bajaensis inside palm inflorescence stem (a); and L. bajaensis adult (b). 
At the peak of the flowering season of the blue fan palm, damage caused by the larva to the inflorescences was very high in the three studied sites $(89 \%, 62 \%$ and 95\% of individual palms presented inflorescence damage in San Pedro Martir, Cataviña and La Libertad, respectively). As the number of palms showing stem damage increased, the number of palms with fruits decreased drastically throughout the sampling period in La Libertad, but not in Cataviña, where the proportion of palms with fruits remained more or less constant during the entire sampling period Figure 4. Palms in San Pedro Martir showed an even distribution of fruit production, but the number of palms with fruits represented no more than the 30\% of the population Figure 4.

Even though damage was high, palms did not stop producing inflorescence stems along the sampling period in the studied sites. No differences were found neither in the number of stems produced $\left(\chi^{2}=0.83, d f=2, P=0.66\right.$; Figure 5(a)), nor in the number of damaged stems between palms on the three sites $\chi^{2}=0.47, d f=2, P=0.79$; Figure 5(b)). In November 2009, 99 palms produced a total of 1607 in Cataviña (Mean $=16.2 \pm 5.4$ stems per palm). This number increased to 2192 at the end of the censuses in September 2010 (Mean $=22.1 \pm 7.9$ stems per palm). In La Libertad 115 individuals produced a total of 1435 stems in November 2009 (Mean $=12 \pm 4.9$ stems per palm), but this number decreased to 1247 in September 2010 (Mean $=10.8 \pm 4.4$ stems per palm). In San Pedro Martir the number of palm trees was larger; we counted 253 and 269 palm trees in four hectares in June and November 2010, respectively, that produced a total of 3364 stems in the first sampling event (Mean = $13.3 \pm 5.9$ stems per palm) and 4278 stems in the second

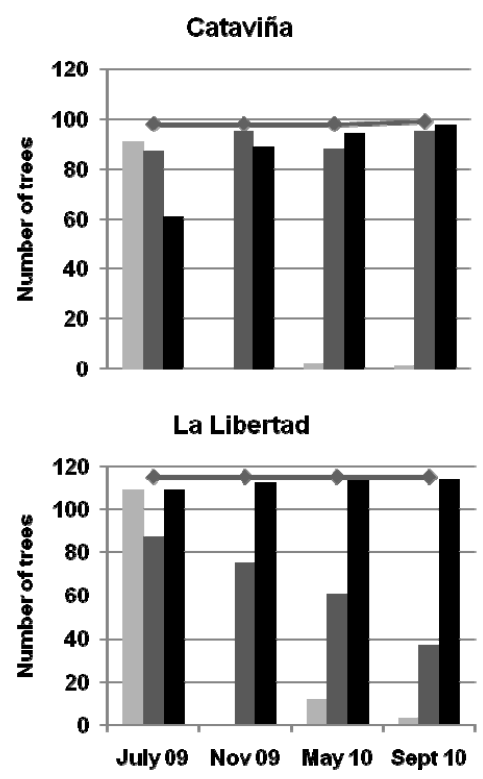

(Mean $=15.9 \pm 8.2$ stems per palm).

In November 2009, 54\% of stems were damaged in Cataviña and the damage level remained more or less constant up to 59\% by the end of September 2010. In La Libertad, $72 \%$ of stems produced showed damage at the beginning of censuses, but the number increased to $90 \%$ at the end of the sampling period. In San Pedro Martir the percentage of damaged stems was $65 \%$ in June 2010 , and increased to $86 \%$ in November 2010. Once again Cataviña showed a different pattern with respect to the other sites.

When the total palm reproductive success from the three populations was calculated, Cataviña showed a significantly higher value than the populations of $\mathrm{La}$ Libertad and San Pedro Martir $\left(\chi^{2}=9.21, d f=2, P=\right.$ 0.01; Figure 5(c)). Although damage to inflorescences was high in all sites, palms continued to produce fruits during the entire sampling period. In Cataviña, $45 \%$ of stems had fruits in November 2009, and this remained more or less constant until the end of censuses in September 2010 (41\%). In contrast, in La Libertad we found that $48 \%$ of stems had fruits in November 2009, but at the end of the censuses only $9 \%$ had fruits. A similar pattern was registered in San Pedro Martir, where only $7.4 \%$ of total stems produced fruits in June 2010, and only $4 \%$ in November 2010. The pattern of precipitation showed a peak during the winter season (December to March, 2010) (Figure 6), being the highest precipitation value $(165.9 \mathrm{~mm})$ registered for Cataviña in January 2010. The occurrence of this water pulse might help explain the continuous stem and fruit production in the Cataviña site.
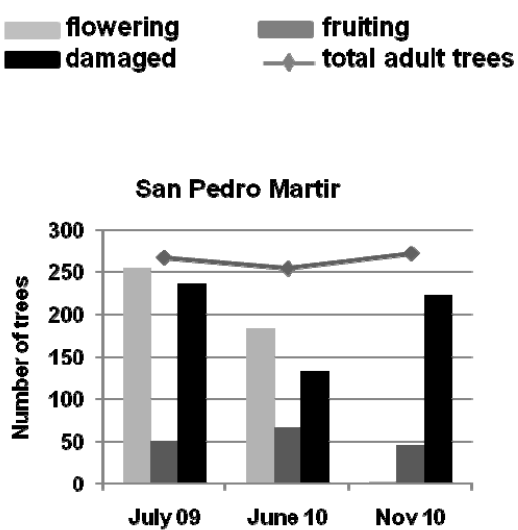

Figure 4. Number of individuals flowering, fruiting, and with inflorescence stems damaged in the study oases of Cataviña, La Libertad, and San Pedro Martir along the sampling period. 
Cataviña
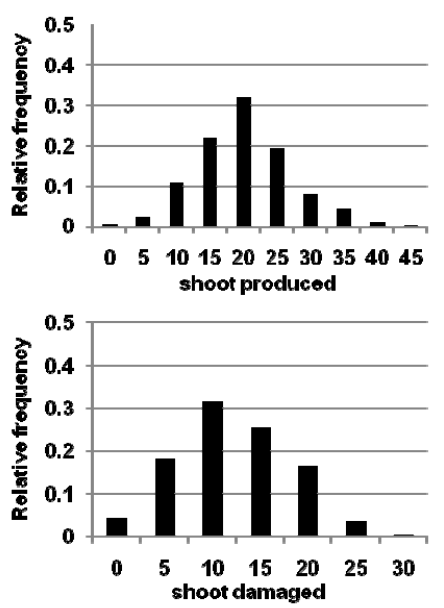

Libertad
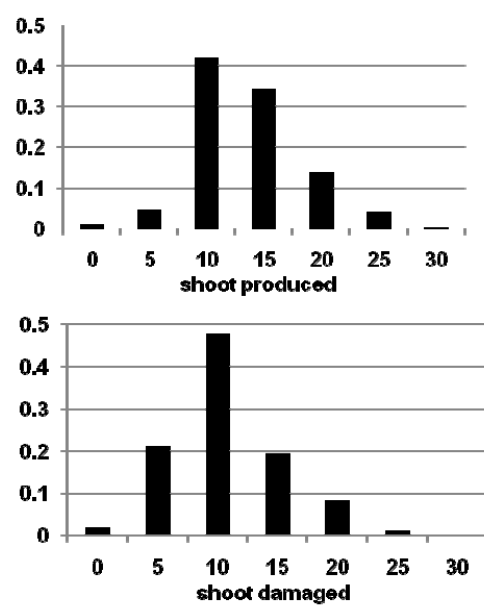

San Pedro Martir

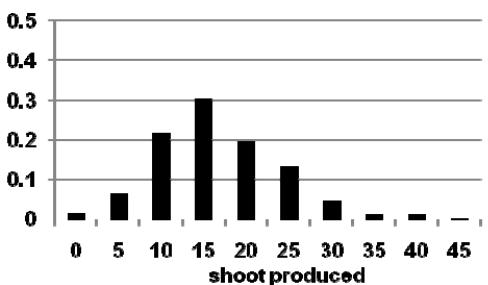

shoot produced

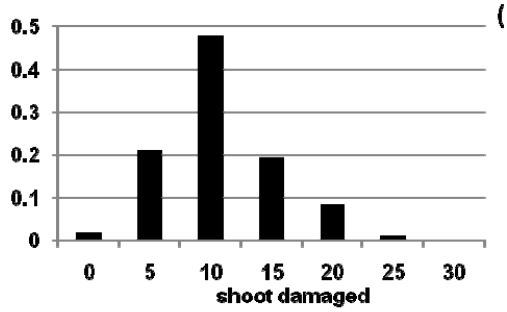

(a)

(c)

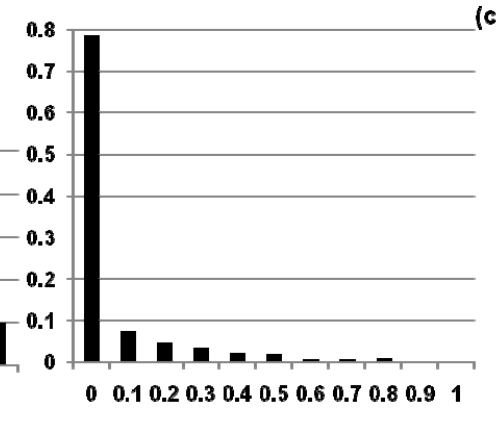

reproductive success

Figure 5. Relative frequency of stems produced (a); damaged (b); and the reproductive success; (c) of palms in Cataviña, La Libertad, and San Pedro Martir populations during the sampling period.

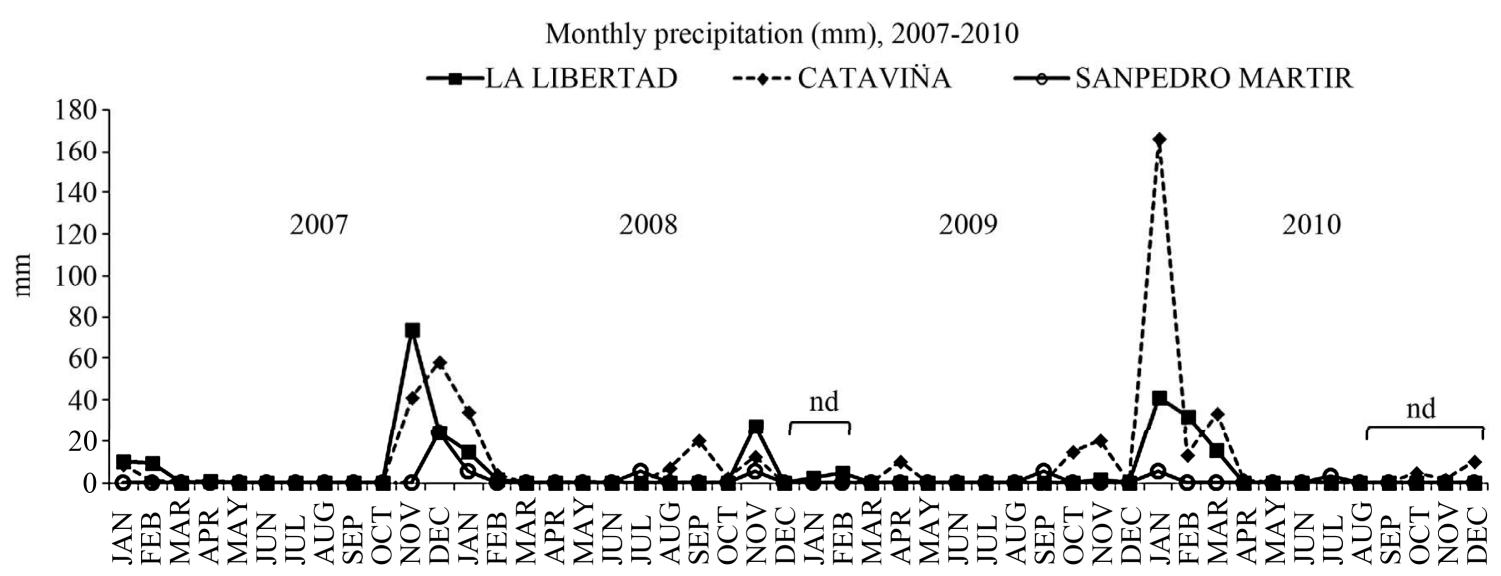

Figure 6. Total precipitation per month $(\mathrm{mm})$ for the period 2007 to 2010, in the three study oases of San Pedro Martir, Cataviña, and La Libertad. Data were obtained from the National Water Commission in Mexico.

\section{Discussion}

This preliminary study reveals and evaluates the impact of a new blue fan palm-insect herbivory interaction at the population and ecosystem level and shows the role of desert oases as resource patches and corridors for insects.

It also represents the first record of a damage produced by an insect that strongly affects the fitness of the blue fan palm populations. As the spatial distribution of popu- lations is affected by the dispersal abilities of the species, interactions among individuals, and/or habitat selection [14], our results of palm damage by L. bajaensis larva suggest that host distribution, temporal climatic variations, and the egg-lying process may be the potential factors involved in the spatial pattern of the adults of this species. Apparently, L. bajaensis has a preference of laying eggs in blue fan palm inflorescence stems, and it 
seems to follow the flowering period of the blue fan palm populations very well in space and time. This study highlights the effects that occasional water pulses have in desert oasis ecosystems by providing an opportunity window of escape from predation for host plant species. Water pulses in deserts trigger short periods of high resource abundance, and they are really the driving force structuring desert ecosystems and influencing interactions. But, because rainfall pulses may vary significantly in frequency and quantity in space and time, this promotes a diversity of responses in life-forms and adaptations.

Based on life history information of $L$. coachella, the closest geographically distributed congener, Brown and Faulkner (1997) [34] suggested that the larva of $L$. $b a$ jaensis feeds on the flowers, buds, and possibly fruits of fan palms of the genus Washingtonia, an observation that probably derives from the fact that within the range of $B$. armata two species of Washingtonia occur ( $W$. filifera (Linden) Wendl. and $W$. robusta Wendl. [35]). However, although Washingtonia palms were flowering at the same time, we never saw $L$. bajaensis larva related with them, nor with any other plant species in our study sites.

Compared with the sites of San Pedro Martir (the northernmost distribution of blue fan palms in this study) and La Libertad (the southernmost distribution), Cataviña received the highest precipitation during the winter season of 2010. In addition, Cataviña is the only alluvial canyon among our studied sites and can be considered an area of high degradation process (with coarse and fine sands constituting the $50 \%-80 \%$ from soil samples taken in the area; E. Wehncke, unpublished data) and probably of high nutrient uptake and redistribution. The most extensive survey of desert vegetation root data showed that rooting depths tend to increase with mean annual precipitation, and that rooting depths tend to be greater in sandy as opposed to clayey or loamy soils [46]. By virtue of their greater access to water, deep-rooted plants may remain active longer and thus continue growth and nutrient uptake [47]. When water runs through the canyons, coarse materials are degraded and transported. Water easily filters into the aquifers deep down below as it runs through this sandy canyon. In contrast, La Libertad and San Pedro Martir are bedrock canyons where water runs very intensely when heavy rains occur. Future soil analyses from these sites will allow a better identification of the type of materials transported, their characteristic composition and origin, as well as studies on root system structure across different plant functional groups and habitats, will help make generalizations on an ecosystem basis.

In the Central Desert Region of Baja California where water scarcity is a critical problem, blue fan palm oases represent the boundaries of many endemic populations of plants and animals, therefore increasing the knowledge on how much these oases are still interconnected is relevant for ensuring the conservation of their biodiversity and the maintenance of the ecological services that these ecosystems provide. Further, long-term herbivore-plant interaction studies coupled with meteorological surveys will provide an interesting approach to detect and predict the impacts that environmental changes will have on these desert ecosystems and the last water reservoirs in this region.

\section{Acknowledgements}

This research was funded by the JiJi Foundation fellowship awarded to E.W. We greatly appreciate the support of the BRCC at the San Diego Natural History Museum. We are grateful to the local people living around oases in all the three sites, and to Víctor Sánchez Sotomayor at Valle the los Cirios Protected Area, CONANP, Mexico, for all the support given during the study. We want to thank N. Jacobson, M. Gastelum and F. Mejía for reviewing this manuscript and providing helpful suggestions that greatly improved it.

\section{REFERENCES}

[1] M. J. Crawley, "Insect Herbivores and Plant Population Dynamics,” Annual Review of Entomology, Vol. 34, 1989, pp. 531-564. doi:10.1146/annurev.en.34.010189.002531

[2] R. Karban and I. T. Baldwin, "Induced Responses to Herbivory,” The University of Chicago Press, Chicago, 1997.

[3] S. M. Louda, K. H. Keeler and R. D. Holt, "Herbivore Influences on Plant Performance and Competitive Interactions,” In: J. M. Grace and D. Tilman, Eds., Perspectives on Plant Competition, Academic Press, New York, 1990, pp. 413-444.

[4] J. L. Maron and E. Crone, "Herbivory: Effects on Plant Abundance, Distribution and Population Growth," Proceedings of the Royal Society of London, Vol. 273, No. 1601, 2006, pp. 2575-2584. doi:10.1098/rspb.2006.3587

[5] J. L. Maron and M. Vila, "When Do Herbivores Affect Plant Invasion? Evidence for the Natural Enemies and Biotic Resistance Hypotheses,” Oikos, Vol. 95, No. 3, 2001, pp. 361-373.

[6] D. Tilman and P. Kareiva, "Spatial Ecology: The Role of Space in Population Dynamics and Interspecific Interactions,” Princeton University Press, New Jersey, USA, 1997. doi:10.1034/j.1600-0706.2001.950301.x

[7] T. Tscharntke and R. Brandl, "Plant-Insect Interactions in Fragmented Landscapes," Annual Review of Entomology, Vol. 49, 2004, pp. 405-430. doi:10.1146/annurev.ento.49.061802.123339

[8] T. Tscharntke, I. Steffan-Dewenter, A. Kruess and C. Thies, "Characteristics of Insect Populations on Habitat Fragments: A Mini Review,” Ecological Research, Vol. 17, No. 2, 2002, pp. 229-239. doi:10.1046/j.1440-1703.2002.00482.x 
[9] E. Leyequien, J. Verrelst, M. Slot, G. Schaepman-Strub, I. M. A. Heitkönig and A. Skidmore, "Capturing the Fugitive: Applying Remote Sensing to Terrestrial Animal Distribution and Diversity," International Journal of Applied Earth Observations, Vol. 9, No. 1, 2007, pp. 1-20. doi:10.1016/j.jag.2006.08.002

[10] E. J. B. McIntire, C. B. Schultz and E. E. Crone, "Designing a Network for Butterfly Habitat Restoration: Where Individuals, Populations and Landscapes Interact," Journal of Applied Ecology, Vol. 44, No. 4, 2007, pp. 725-736.

[11] M. F. Coombs and M. A. Rodriguez, "A Field Test of Simple Dispersal Models as Predictors of Movement in a Cohort of Lake-Dwelling Brook Charr," Journal of Animal Ecology, Vol. 76, No. 1, 2007, pp. 45-57. doi:10.1111/j.1365-2656.2006.01188.x

[12] S. Eber, "Bottom-Up Density Regulation in the Holly LeafMiner Phytomyza Ilicis," Journal of Animal Ecology, Vol. 73, No. 5, 2004, pp. 948-958. doi:10.1111/j.0021-8790.2004.00867.x

[13] M. Rodeghiero and A. Battisti, "Inter-Tree Distribution of the Spruce Web Spinning Sawfly, Cephalcia abietis, at Endemic Density," Agricultural and Forest Entomology, Vol. 2, No. 4, 2000, pp. 291-296. doi:10.1046/j.1461-9563.2000.00078.x

[14] F. Vinatier, P. Tixier, P. F. Duyck and F. Lescourret, "Factors and Mechanisms Explaining Spatial Heterogeneity: A Review of Methods for Insect Populations," Methods in Ecology and Evolution, Vol. 2011, No. 2, 2011, pp. 11-22. doi:10.1111/j.2041-210X.2010.00059.x

[15] S. D. Fretwell, "The Regulation of Plant Communities by the Food Chains Exploiting Them," Perspectives in Biology and Medicine, Vol. 20, 1977, pp. 421-425.

[16] S. D. Fretwell, "Food Chain Dynamics: The Central Theory of Ecology?” Oikos, Vol. 50, No. 3, 1987, pp. 291301. doi:10.2307/3565489

[17] N. G. Hairston, F. E. Smith and L. B. Slobodkin, "Community Structure, Population Control, and Competition," American Naturalist, Vol. 94, No. 879, 1960. pp. 421-425. doi:10.1086/282146

[18] L. Oksanen, S. D. Fretwell, J. Arruda and P. Niemela, "Exploitation Ecosystems in Gradients of Primary Productivity," American Naturalist, Vol. 118, No. 2, 1981, pp. 240-261. doi:10.1086/283817

[19] L. Oksanen, "Predation, Herbivory, and Plant Strategies along Gradients of Primary Productivity,” In: J. B. Grace and T. Tilman, Eds., Perspectives on Plant Competition, Academic Press, London, 1990, pp. 445-474.

[20] L. Oksanen and T. Oksanen, "The Logic and Realism of the Hypothesis of Exploitation Ecosystems," American Naturalist, Vol. 155, No. 6, 2000, pp. 703-723. doi:10.1086/303354

[21] G. Oba, Z. Mengistu and N. C. Stenseth, “Compensatory Growth of the African Dwarf Shrub Indigofera Spinosa Following Simulated Herbivory," Ecological Applications, Vol. 10, No. 4, 2000, pp. 1133-1146. doi:10.1890/1051-0761(2000)010[1133:CGOTAD]2.0.C $\underline{\mathrm{O} ; 2}$

[22] B. A. Roundy and G. B. Ruyle, "Effects of Herbivory on
Twig Dynamics of a Sonoran Desert Shrub Simmondsia chinensis (Link) Schn,” Journal of Applied Ecology, Vol. 26, No. 2, 1989, pp. 701-710. doi:10.2307/2404094

[23] F. Tiver and M. H. Andrew, "Relative Effects of Herbivory by Sheep, Rabbits, Goats and Kangaroos on Recruitment and Regeneration of Shrubs and Trees in Eastern South Australia,” Journal of Applied Ecology, Vol. 34, No. 4, 1997, pp. 903-914. doi:10.2307/2405281

[24] G. A. Roth, W. G. Whitford and Y. Steinberger, “Jackrabbit (Lepus californicus) Herbivory Changes Dominance in Desertified Chihuahuan Desert Ecosystems," Journal of Arid Environments, Vol. 70, No. 3, 2007, pp. 418-426. doi:10.1016/j.jaridenv.2007.01.009

[25] J. Tort, C. M. Campos and C. E. Borghi, "Herbivory by Tuco-Tucos (Ctenomys mendocinus) on Shrubs in the Upper Limit of the Monte Desert (Argentina),” Mammalian, Vol. 68, No. 1, 2004, pp. 15-21.

[26] T. D. Schowalter, "Insect Ecology: An Ecosystem Approach,” 2nd Edition, Elsevier, Burlington, 2006.

[27] S. M. Louda, "Distribution Ecology: Variation in Plant Recruitment over a Gradient in Relation to Insect Seed Predation,” Ecological Monographs, Vol. 52, No. 1, 1982, pp. 25-41. doi:10.2307/2937343

[28] T. E. X. Miller, S. M. Louda, K. A. Rose and J. O. Eckberg, "Impacts of Insect Herbivory on Cactus Population Dynamics: Experimental Demography across an Environmental Gradient,” Ecological Monographs, Vol. 79, No. 1, 2009, pp. 155-172. doi:10.1890/07-1550.1

[29] M. Takahashi and N. Huntly, "Herbivorous Insects Reduce Growth and Reproduction of Big Sagebrush (Artemisia tridentata)," Arthropod and Plant Interactions, Vol. 4, No. 4, 2010, pp. 257-266. doi:10.1007/s11829-010-9108-1

[30] E. V. Wehncke, X. López-Medellín and E. Ezcurra, "Patterns of Frugivory, Seed Dispersal and Predation of Blue Fan Palms (Brahea armata) in Oases of Northern Baja California,” Journal of Arid Environments, Vol. 73, No. 9, 2009, pp. 773-783. doi:10.1016/j.jaridenv.2009.03.007

[31] E. V. Wehncke, X. López-Medellín and E. Ezcurra, “Blue Fan Palm Distribution and Seed Removal Patterns in Three Desert Oases of Northern Baja California, Mexico,” Plant Ecology, Vol. 208, No. 1, 2010, pp. 1-20. doi:10.1007/s11258-009-9682-4

[32] E. V. Wehncke, J. Rebman, X. López-Medellín and E. Ezcurra, "Sierra de La Libertad: A Major Transition between Two Desert Regions in Baja California, Mexico," Botanical Sciences, Vol. 90, No. 3, 2012, pp. 239-261.

[33] R. A. Minnich, E. Franco-Vizcaino and J. M. SalazarCeseña, "Distribution and Regional Ecology of Californian Palm Oases Interpreted from Google Earth Images,” Aliso: A Journal of Taxonomic and Evolutionary Botany, Vol. 29, No. 1, 2011, pp. 1-12.

[34] J. W. Brown and D. K. Faulkner, “A New Species of Litoprosopus (Lepidoptera: Noctuidae) from Baja California, Mexico," The Pan-Pacific Entomologist, Vol. 73, No. 2, 1997, pp. 122-126.

[35] I. Wiggins, “Flora of Baja California,” Stanford University Press, Stanford, California, 1980. 
[36] R. S. Felger and E. Joyal, "The Palms (Arecaceae) of Sonora, Mexico,” Aliso, Vol. 18, 1999, pp. 1-18.

[37] F. Shreve, "Vegetation of the Sonoran Desert," Carnegie Institution of Washington Publication 591, Carnegie Institution, Washington DC, 1951.

[38] S. H. Bullock, "Seasonality, Spatial Coherence and History of Precipitation in a Desert Region of Baja California Peninsula,” Journal of Arid Environments, Vol. 53, No. 2, 2003, pp. 169-182. doi:10.1006/jare.2002.1040

[39] W. Speidel and C. M. Naumann, "A Survey of FamilyGroup Names in Noctuoid Moths (Insecta: Lepidoptera). Systematic and Biodiversity, Vol. 2, No. 2, 2004, pp. 191221. doi:10.1017/S1477200004001409

[40] J. W. Brown, "Preliminary Assessment of Lepidoptera Diversity on the Peninsula of Baja California, Mexico, with a List of Documented Species," Folia Entomológica Mexicana, Vol. 43, No. 1, 2004, pp. 87-114.

[41] R. Poole, "Lepidopterorum Catalogus (New Series), Fascicle 118: Noctuidae,” E. J. Brill/Flora and Fauna Publishing, Leiden, 1989.

[42] J. Dransfield, I. K. Ferguson and N. W. Uhl, "The Cory- phoid Palms: Patterns of Variation and Evolution," Annals of the Missouri Botanical Garden, Vol. 77, No. 4, 1990, pp. 802-815. doi:10.2307/2399672

[43] A. Henderson, "Evolution and Ecology of Palms," The New York Botanical Garden Press, New York, 2002.

[44] A. Henderson, G. Galeano and R. Bernal, "Field Guide to the Palms of the Americas," Princeton University Press, Princeton, 1995.

[45] J. P. Rebman and N. C. Roberts, "Baja California Plant Field Guide,” 3rd Edition, San Diego Natural History Museum, Sunbelt Publications, 2012.

[46] H. J. Schenk and R. B. Jackson, "The Global Biogeography of Roots,” Ecological Monographs, Vol. 72, No. 3, 2002, pp. 311-328. doi:10.1890/0012-9615(2002)072[0311:TGBOR]2.0.CO;2

[47] M. S. Seyfried, S. Schwinning, M. A. Walvoord, W. T. Pockman, B. D. Newman, R. B. Jackson and F. M. Phillips, "Ecohydrological Control of Deep Drainage in Arid and Semiarid Regions,” Ecology, Vol. 86, No. 2, 2005, pp. 277-287. doi:10.1890/03-0568 